\title{
Experimental Investigation of Surface Color Changes in Vacuum Evaporation Process for Gold-like Stainless Steel
}

\author{
Baojian Yang ${ }^{1, \mathrm{a}}$ and $\mathrm{Xin} \mathrm{He}^{2}$ \\ ${ }^{1}$ School of Mechatronic Engineering, Wuyi University, Jiangmen, China \\ ${ }^{2}$ School of Applied Physics \& Materials, Wuyi University, Jiangmen, China
}

\begin{abstract}
In order to reduce the environmental pollution caused by the three wastes during the process of electroplating of gold-like film on stainless steel, in this paper, the "vacuum evaporation and annealing" composite technologies were adopted to evaporate gold-like film in 16 stainless steel 304 substrates, and electronic color cards and color software were also used for analyzing the color and luster of the gold-like film. Experiments shows that the negative pressure, annealing temperature and mass fraction of the double copper alloys have influence on preparation of imitation in assaying the fineness of gold film, the annealing temperature has significant effects on imitation in assaying the fineness of gold film.
\end{abstract}

\section{Introduction}

As the living standard improves gradually, the requirement of the people for appearance of product become higher and hither, and the single color appearance of the plain stainless steel is unable to meet the needs of the consumers. Gold-like material, which is also called artificial gold, not only can match the 16-22 K gold color, but also has good corrosion resistance, wear resistance and good processability[1].

Theoretical research and engineering practice show that the superficial tissue with fine and uniform grain can make the general performance of material improved greatly[2,3]. By coating a dense copper film with fine grains on the stainless steel surface, the physical \& chemical properties, mechanical properties and appearance of the stainless steel will be improved generally[4,5]. However, most gold-like stainless steels are processed through the electroplating technology presently, and the hexavalent chromium $\left(\mathrm{Cr}^{6+}\right)$ in the process of electroplating will do great harm to human body[6].

In the paper, the vacuum deposition technology will be introduced to the preparation of gold-like stainless steel, and the vacuum evaporation process will be also discussed, which will be of great significance in preparing the gold-like stainless steel.

\section{Experimental preparation}

For comparative study, two kinds of copper alloys were used as the source of target materials, namely, brass $(\mathrm{Cu}$ zinc alloy) and aluminum bronze ( $\mathrm{Cu}-\mathrm{Al}$ alloy), and their compositions are as shown in Table 1 . The substrate

\footnotetext{
a Corresponding author: kurt.yang@163.com
}

material is 304 stainless steel, with size of $30 \mathrm{~mm} \times 60$ $\mathrm{mm} \times 0.2 \mathrm{~mm}$. Moreover, the inductive heating evaporator was designed (as shown in Figure 1).

Table 1. Compositions of two copper alloys.

\begin{tabular}{|c|c|c|c|c|c|}
\hline $\begin{array}{c}\text { Chemical } \\
\text { composition }\end{array}$ & $\mathrm{Al}$ & $\mathrm{Zn}$ & $\mathrm{Ni}$ & $\mathrm{Si}$ & $\mathrm{Cu}$ \\
\hline $\begin{array}{c}\text { No.1 } \\
\text { Sample }\end{array}$ & $\begin{array}{c}5.5- \\
6.5\end{array}$ & & 1.5 & $\begin{array}{c}0.3- \\
0.5\end{array}$ & margin \\
\hline $\begin{array}{c}\text { No.2 } \\
\text { Sample }\end{array}$ & $1-2$ & $5-10$ & 1 & & margin \\
\hline
\end{tabular}

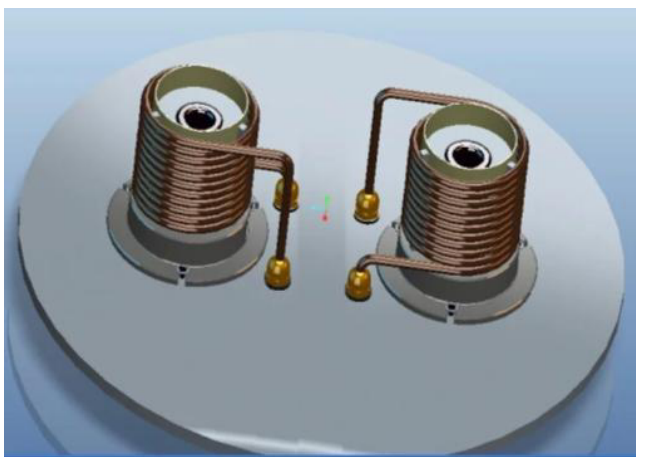

Figure 1. Structure of the Inductive Heating Evaporator

\section{Experiment process}

For the orthogonal experiment, the L16 (45) orthogonal table was selected (as shown in Table 2). Figure 2 shows the whole experimental process of vacuum evaporation of gold-like stainless steel.

Firstly, all the stainless steel substrates are cleaned by ultrasonic wave with acetone, ethanol and deionized 
water successively for 10 minutes, and then they are fixed on the substrate shelf after being dried at $120{ }^{\circ} \mathrm{C}$ in the

Table 2 Orthogonal experiment scheme for preparation of gold-like stainless steel

\begin{tabular}{|c|c|c|c|c|}
\hline Element & $\begin{array}{c}\text { Pressure of } \\
\text { vacuum } \\
\text { chamber(Pa) }\end{array}$ & $\begin{array}{c}\text { Annealing } \\
\text { Temperature }\left({ }^{\circ} \mathrm{C}\right)\end{array}$ & $\begin{array}{c}\text { Brass } \\
\text { mass } \\
\text { fraction }\end{array}$ & $\begin{array}{c}\text { Aluminum } \\
\text { bronze } \\
\text { mass } \\
\text { fraction }\end{array}$ \\
\hline 1 & $9 \times 10^{-4}$ & 230 & 3 & 0.5 \\
\hline 2 & $9 \times 10^{-4}$ & 320 & 5 & 1 \\
\hline 3 & $9 \times 10^{-4}$ & 410 & 7 & 1.5 \\
\hline 4 & $9 \times 10^{-4}$ & 500 & 9 & 2 \\
\hline 5 & $4 \times 10^{-3}$ & 230 & 5 & 1.5 \\
\hline 6 & $4 \times 10^{-3}$ & 320 & 3 & 2 \\
\hline 7 & $4 \times 10^{-3}$ & 410 & 9 & 0.5 \\
\hline 8 & $4 \times 10^{-3}$ & 500 & 7 & 1 \\
\hline 9 & $7 \times 10^{-3}$ & 230 & 7 & 2 \\
\hline 10 & $7 \times 10^{-3}$ & 320 & 9 & 1.5 \\
\hline 11 & $7 \times 10^{-3}$ & 410 & 3 & 1 \\
\hline 12 & $7 \times 10^{-3}$ & 500 & 5 & 0.5 \\
\hline 13 & $1 \times 10^{-2}$ & 230 & 9 & 1 \\
\hline 14 & $1 \times 10^{-2}$ & 320 & 7 & 0.5 \\
\hline 15 & $1 \times 10^{-2}$ & 410 & 5 & 2 \\
\hline 16 & $1 \times 10^{-2}$ & 500 & 3 & 1.5 \\
\hline & & & & \\
\hline
\end{tabular}

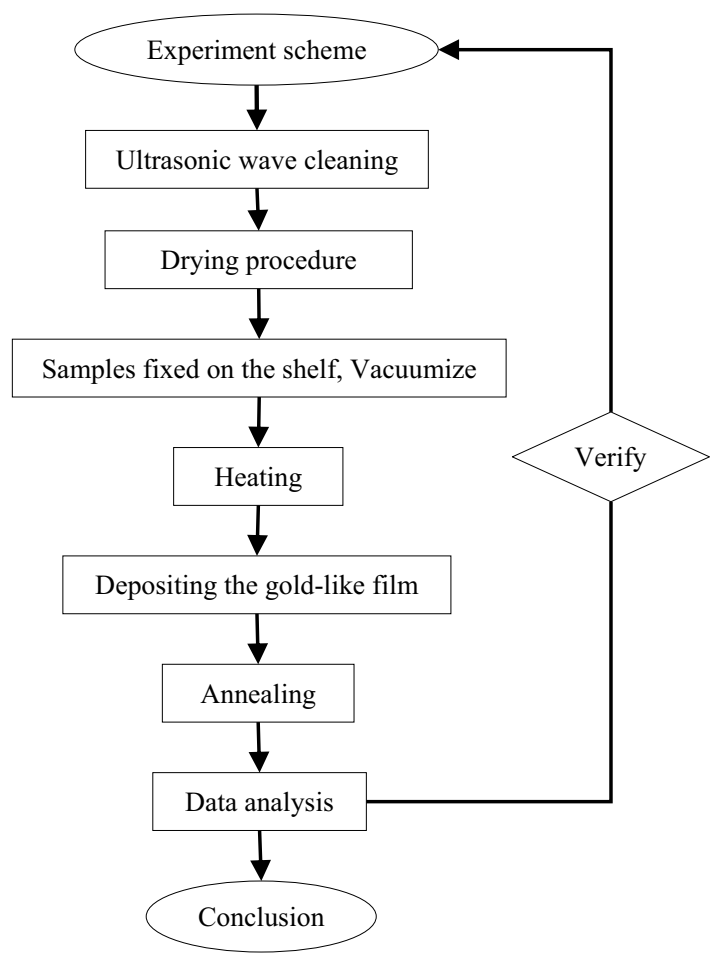

Figure 2. Flow Chart of Producing Gold-like Stainless Steel

oven. Secondly, both the brass wire and aluminum bronze wire are tangled around two electrodes respectively and the inductance heating begins when the pressure of vacuum chamber goes down to the setting value. Then the $\mathrm{Cu}, \mathrm{Zn}, \mathrm{Al}$ and $\mathrm{Ni}$ atoms interact with each other and deposit on the substrates while the temperature rises to about $1000{ }^{\circ} \mathrm{C}$. Finally, the gold-like metallic film is prepared on the surface of stainless steel. After all, all samples are put into the muffle furnace to conduct annealing treatment. Figure 3 shows the evaporation and annealing equipment used in the experiment.

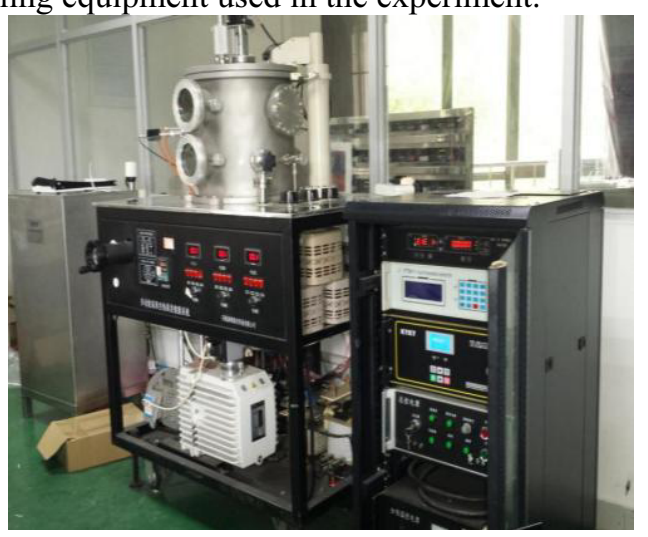

(a) Vacuum coating equipment

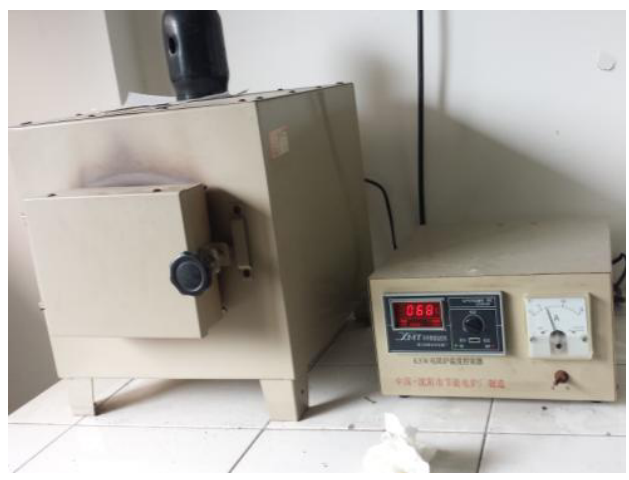

(b) The oven

Figure 3. Vacuum Coating Equipment \& Muffle Furnace

\section{Results}

After the orthogonal experiment, 16 samples are prepared, as shown in Figure 4.

In order to study the influence of vacuum pressure, annealing temperature and mass fraction on the color similarity of gold-like film, Power Shot SX50HS highdefinition camera was used to get images of all samples,

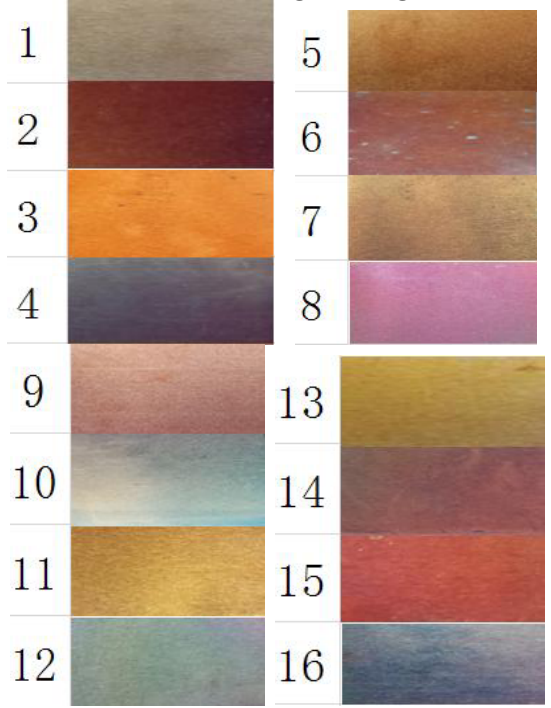

Figure 4. Experiment Samples 
and then software Get Color was adopted to get 5 color values for average from each image.

Since the color values got by the software are of RGB color space, so they were converted to HSV color space in order to match the human senses(as shown in Figure 5)[7]. The coordinates of the RGB color space is ( $R, G$, $\mathrm{B})$, and MAX, MIN represent the largest and the smallest value of the R, G, B respectively. However, In HSV color $\operatorname{space}(H, S, V), H \in\left[0,360^{\circ}\right), S \in[0,1]$ and $\mathrm{V} \in[0,1]$, and the mathematical conversion formula are shown as in Equation (1).

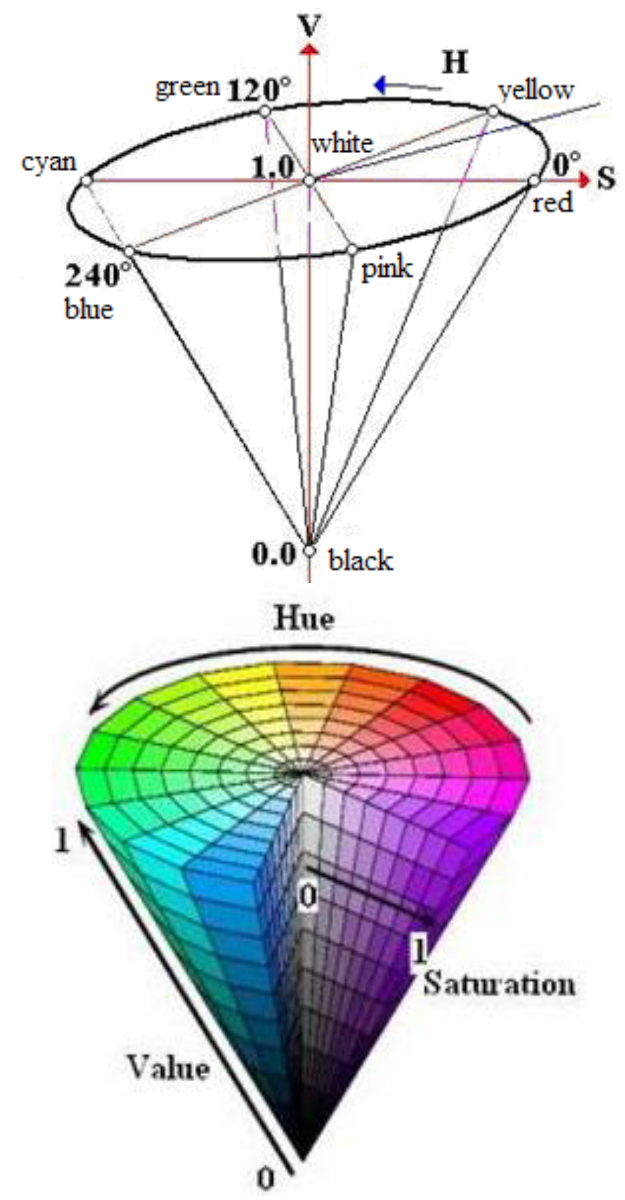

$$
H= \begin{cases}0^{\circ}, & \text { IF MAX }=\text { MIN } \\ 60^{\circ} \times \frac{G-B}{M A X-M I N}+0^{\circ}, & \text { IF MAX }=R \text { and } G \geq B \\ 60^{\circ} \times \frac{G-B}{M A X-M I N}+360^{\circ}, & \text { IF MAX }=R \text { and } G<B \\ 60^{\circ} \times \frac{B-R}{M A X-M I N}+120^{\circ}, & \text { IF MAX }=G \\ 60^{\circ} \times \frac{R-G}{M A X-M I N}+240^{\circ}, & \text { IF MAX }=B \\ S= \begin{cases}0, & \text { IF MAX }=0 \\ \frac{M A X-M I N}{M A X}, & \text { OTHERWISE }\end{cases} \\ V=M A X \times \frac{100}{255} \times 100 \%\end{cases}
$$

In the paper, the Euclidean distance $\Delta S$ (i.e. color aberration) was adopted to judge the similarity between the samples $\left(\mathrm{H}_{\mathrm{s}}, \mathrm{S}_{\mathrm{s}}, \mathrm{V}_{\mathrm{s}}\right)$ and the standard gold $\left(\mathrm{H}_{\mathrm{g}}, \mathrm{S}_{\mathrm{g}}, \mathrm{V}_{\mathrm{g}}\right)$, the smaller $\triangle \mathrm{S}$ is, the more similar they are. Its formula is as in (2) [8]:

$$
\Delta S=\sqrt{\left(H_{\mathrm{s}}-H_{\mathrm{g}}\right)^{2}+\left(S_{\mathrm{s}}-S_{\mathrm{g}}\right)^{2}+\left(V_{\mathrm{s}}-V_{\mathrm{g}}\right)^{2}}
$$

Through this method, Experimental data were obtained, and then data variance analysis was conducted.

In Table 3, it reveals that in the 95\% confidence level, the influence of annealing temperature on preparation of gold-like stainless steel is notable, and the influence of other factors are not obvious. From Figure 6, it could be concluded that the color aberration between the sample color and golden color first increases then decreases along with the increase of annealing temperature, and it reaches the minimal value around $410^{\circ} \mathrm{C}$, then it increases sharply to 250 .

Figure 5. HSV Cone Space Model

Table 3. Orthogonal experiment data variance analysis table

\begin{tabular}{|c|c|c|c|c|c|c|}
\hline Item & Sum-of-squares & $\begin{array}{c}\text { Degree of } \\
\text { freedom }\end{array}$ & Mean square & $\begin{array}{c}\text { Proportion of Sum- } \\
\text { of-squares }\end{array}$ & $F$ & $F(0.05)$ \\
\hline A & 295.7133187 & 3 & 98.571106 & 0.001754784 & 0.032730826 & 9.28 \\
\hline B & 151513.4987 & 3 & 50504.5 & 0.899091952 & 16.77016795 & 9.28 \\
\hline C & 3302.563269 & 3 & 1100.8544 & 0.019597647 & 0.365541956 & 9.28 \\
\hline D & 4371.878119 & 3 & 1457.2927 & 0.025943038 & 0.483898399 & 9.28 \\
\hline error & 9034.703719 & 3 & 3011.5679 & & & \\
\hline $\begin{array}{c}\text { Sum } \\
\text { total }\end{array}$ & 168518.3571 & 15 & & & & \\
\hline
\end{tabular}




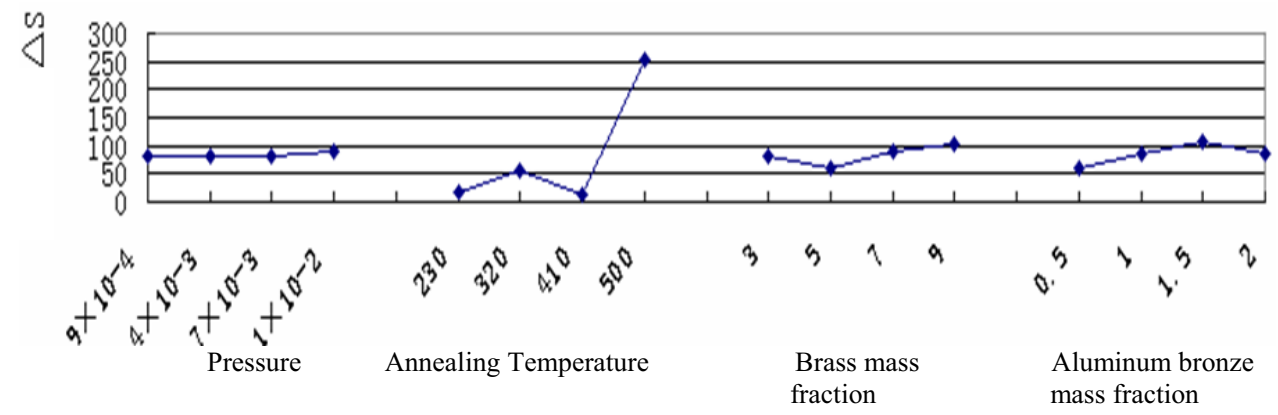

Figure 6. Influence of Different Factors on the Euclidean Distance

Finally, the AEP Universal 3D Profilometer was used to measure the thickness of the gold-like film on the cross section of No.11 and No.13 samples, as shown in Figure 7. In Figure 8, the thickness fluctuates among the testing points on No.11 and No.13 samples, and it reveals the thickness of No.11 and No.13 samples are 0.3 um and 0.6 um, and the thicker the film became, the darker its color got.

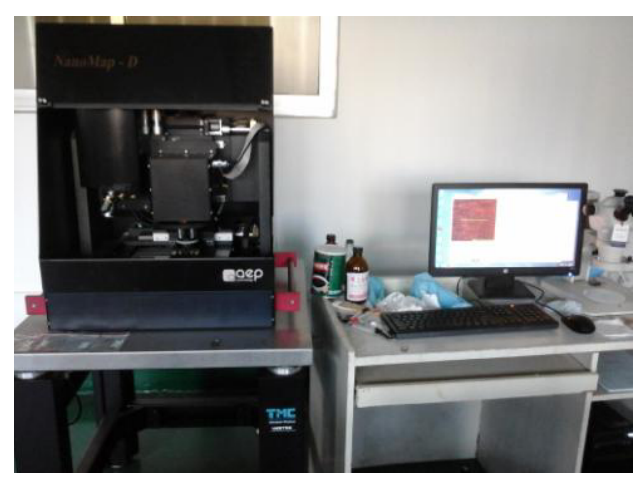

(a) AEP Universal 3D Profilometer

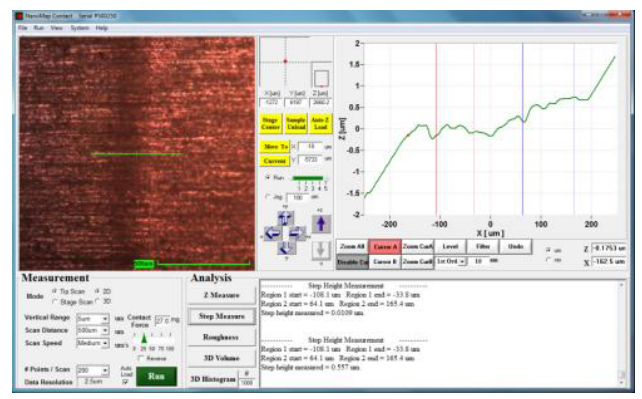

(b) Measurement system interface

Figure 7. Thichness Measurement of the Gold-like Film

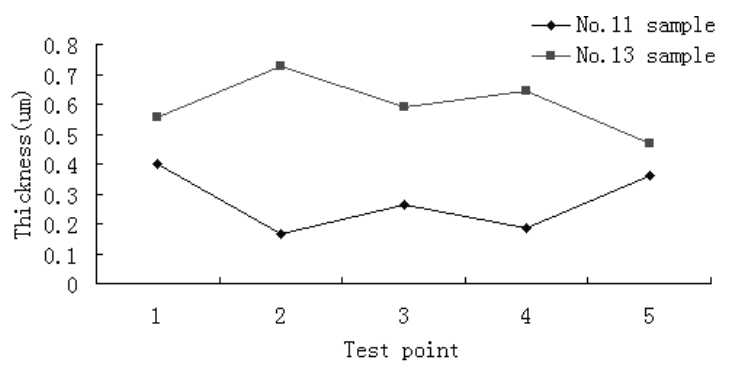

Figure 8. Thickness of the Gold-like Film

\section{Conclusion}

Through the orthogonal experimental investigation of vacuum evaporation and annealing compound process and study of the color aberration with the electronic RHS color chart and colorimetric analysis software for the gold-like thin film on 304 stainless steel substrate, conclusions can be obtained as follows:

(1) By compound process of vacuum evaporation and annealing, the gold-like film can be prepared on the stainless steel surface, and under the conditions that vacuum chamber pressure is of $7 \times 10^{-3} \mathrm{~Pa}$, brass and aluminum bronze's mass fraction ratio is of $3: 1$, annealing temperature is of $410{ }^{\circ} \mathrm{C}$, the gold-like film prepared can match the $16-22 \mathrm{~K}$ gold's color well.

(2) The color similarity of gold-like film prepared in the paper is influenced by the vacuum chamber pressure, annealing temperature and the ratio of brass/aluminum bronze mass fraction. Especially, the annealing temperature has the greatest influence on the color similarity.

(3) The thickness of gold-like film on the cross section of No.11 and No.13 samples are 0.3 um and $0.6 \mathrm{um}$, and there exists a directly proportional relationship between the thickness and the color similarity with the gold.

\section{References}

1. H.P. Liu, Y.S.Chen, R.S.Wen, and Y. L. Zhu. Study on making technology of copper particles with golden color. Jiangxi Nonferrous Metals. Vol.14,No.4, (2000)

2. B.X. Xu and J.L.Wu. Effects of neodymium on the size of silver nano-particles prepared by vacuum deposition. Rare metal materials and engineering. Vol 32,No 10(2003)

3. J.Ma, J.Shen, X.G.Mao and B.X.Yan. InterDiffusion of $\mathrm{Mg}$ and $\mathrm{Zn}$ in Vacuum-Evaporated $\mathrm{Mg}$ Films on Zn Coated Steel Substrates. Journal of Vacuum Science and Technology. 33(2) (2013)

4. Q.He, J.Q.Liu, C.S.Yang, Y.G. Li and Y.F. Rui. Study on preparation of nanopowder-doped PARYLENE functional films in vacuum. VACUUM. 48(1) (2011)

5. J.Ma, X.M.Jia and J.Shen. Growth and Annealing of Zn-Mg Alloy Thick Films on Steel. Journal of Vacuum Science and Technology. 32(4), (2012)

6. B.Q.Chen. Vacuum surface treatment technology. Taipei: Chuansheng Press. ch.3. (1992)

7. H. Miki,T. Takeno and T. Sugawara. A DLC/WDLC Multilayered Structure for Strain Sensing 
Applications. Diamond \& Related Materials. 17, (2008)

8. I.I. Beilis, Y. Koulik, R.L. Boxman and D. Arbilly. $\mathrm{Al}$ and $\mathrm{Zn}$ film deposition using a vacuum arc plasma source with a refractory anode. Surface \& Coatings Technology. 205,

(2010) 